\title{
PENGARUH PRAKTIK KERJA LAPANGAN TERHADAP SOFT SKILL SISWA SMK BIDANG KEAHLIAN JASA BOGA DI KOTA MALANG
}

\author{
Ria Cahya Mustika \\ Nunung Nurjanah \\ Lismi Animatul Chisbiyah
}

\begin{abstract}
Abstrak: Tujuan penelitian untuk mengetahui: (1) pengaruh PKL terhadap soft skill; dan (2) berapa besar pengaruh PKL terhadap soft skill siswa SMK Bidang Keahlian Jasa Boga di Kota Malang. Populasi penelitian siswa SMK Bidang Keahlian Jasa Boga yang sudah melaksanakan PKL dengan jumlah sampel 127 responden. Teknik pengumpulan data menggunakan kuesioner. Teknik analisis data menggunakan analisis regresi linier sederhana dan analisis faktor. Hasil penelitian menunjukkan bahwa PKL berpengaruh terhadap soft skill siswa SMK Bidang Keahlian Jasa Boga di Kota Malang sebesar 50,50\%. Keterampilan pemecahan masalah merupakan faktor yang paling mewakili soft skill dengan nilai ekstraksi 93,60\%, dibandingkan keterampilan komunikasi, dan berpikir kritis $88,40 \%$, keterampilan memahami antar pribadi $76,20 \%$, dan keterampilan komunikasi tertulis $73,90 \%$.
\end{abstract}

Kata-kata Kunci: Praktik Kerja Lapangan (PKL), soft skills

Abstract: Influence of Field Work Practice on Soft Skill Students SMK Area Expertise of Boga Service in Malang City. The study aimed (1) the influence of street vendors on soft skills; (2) how much influence of street vendors to soft skill of students of Vocational Culinary School in Malang. The research population of students of Vocational Culinary School that have implemented street vendors with a total sample 127 respondents. Data collection techniques using questionnaires. Data analysis techniques used simple linear regression analysis and factor analysis. The results showed that the street vendors have an effect on the soft skill of the vocational students of the Vocational Culinary Schoo in Malang City by 50.5\%. Problem solving skills are the most representative of soft skills with a $93.6 \%$ extraction rate, compared to communication skills, and $88.4 \%$ critical thinking, interpersonal skills of $76.2 \%$, and $73.9 \%$ written communication skills.

Keywords: Field Work Practice (PKL), soft skills

$\mathrm{S}$ Ekolah Menengah Kejuruan sebagai sekolah yang mempersiapkan siswa menjadi tenaga kerja tingkat menengah yang mempunyai pengetahuan, keterampilan, keahlian di bidang produktif dan akhirnya mempunyai kesiapan kerja setelah selesai pendidikannya (Basuki, 2012). Data pada tahun 2015 di Kota Malang, tingkat pengangguran terbuka menurut tingkat pendidikan, SMK menempati

Ria Cahya Mustika adalah mahasiswa Jurusan Teknologi Industri, Universitas Negeri Malang. Alamat Kampus: Jl. Semarang No. 5 Malang 65145. Email: riacahya17@gmail.com. Nunung Nurjanah dan Lismi Animatul Chisbiyah adalah Dosen Jurusan Teknologi Industri Fakultas Teknik Universitas Negeri Malang. Alamat Kampus: Jl. Semarang No. 5 Malang 65145. 
posisi kedua sebanyak 25,48 persen dari 29.606 ribu pengangguran (Badan Pusat Statistik, 2015), sementara menurut Disnaker (2011) tingkat pengangguran terbuka menurut tingkat pendidikan sampai dengan tahun 2011, SMK diposisi keempat sebesar 10,5 persen.

Kualitas lulusan SMK yang dibutuhkan oleh dunia Industri adalah lulusan yang memiliki kecakapan hidup (life skill) meliputi hard skill dan soft skill (Depdiknas, 2004). Depdiknas (2004) membagi kecakapan hidup menjadi dua, kecakapan hidup generik meliputi: (1) Kesadaran diri banyak terkait dengan sikap, (2) Kecakapan berpikir, (3) Kecakapan komunikasi, dan (4) dan kecakapan hidup spesifik dan kecakapan spesifik, yang menunjuk dalam bidang yang ditekuni. Pernyataan yang sama juga disampaikan oleh (Tsai, 2013) hasil penelitiannya menyatakan bahwa pengembangan tes keterampilan generik yang digunakan ACER dilakukan melalui empat bidang, yaitu; (1) komunikasi tertulis, (2) berpikir kritis, (3) pemecahan masalah, dan (4) keterampilan memahami antar pribadi.

SMK bertujuan menghasilkan lulusan yang memiliki pengetahuan, keterampilan dan siap kerja dibidangnya diwujudkan dengan cara menyelenggarakan program Pendidikan Sistem Ganda (PSG) atau yang lebih dikenal dengan Praktek Kerja Lapangan (PKL). PKL adalah penyelenggaraan diklat dikelola bersama antara SMK dengan dunia usaha/dunia industri sebagai institusi pasangan mulai dari perencanaan, pelaksanaan hingga evaluasi (Dikmenjur, 2008). Institusi pasangan (IP) bidang keahlian Tata Boga yang digunakan tempat pelaksanaan program pendidikan sistem ganda (PSG) diantaranya: restoran, hotel, catering, dan bakery (Retnoningsih, 2011).

Setelah melaksanan praktik kerja lapangan siswa juga diharapkan dapat memiliki, keterampilan bekerja maupun keterampilan bersikap, tetapi pada kenya- taannya masih ada siswa yang belum mendapat pengalaman sesuai dengan harapan. Hal yang sama dikemukakan juga dalam hasil kajian yang diadakan oleh (Direktorat Pembinaan SMK, 2008) bahwa masih terdapat kesenjangan kompetensi antara apa yang diperoleh di sekolah kejuruan dengan kebutuhan riil industri. Kelemahan lulusan SMK tersebut mengakibatkan tidak terserap dalam dunia kerja. Oleh karena itu, perlu perubahan orientasi mutu lulusan SMK yang selama ini hanya berorientasi pada hard skill, perlu dimasukkan juga unsur pengembangan soft skill yang sangat diperlukan dunia usaha atau dunia industri. Neff dan Citrin dalam (Utaminingsih, 2011) bahwa kebutuhan dunia usaha atau dunia industri dalam soft skill dan peranan soft skill terhadap kesuksesan seseorang dalam kehidupan adalah 20,00\% hard skill dan $80,00 \%$ soft skill.

Melihat masalah tersebut, peneliti melakukan kajian apakah pengalaman PKL dapat mempengaruhi kemampuan soft skill yang dimiliki siswa SMK Jasa Boga untuk mengetahui: (1) pengaruh PKL terhadap soft skill; dan (2) berapa besar pengaruh PKL terhadap soft skill siswa SMK Bidang Keahlian Jasa Boga di Kota Malang.

\section{METODE}

Penelitian ini merupakan penelitian kuantitatif. Populasi dalam penelitian ini merupakan seluruh siswa SMK Negeri 3 Malang, SMK Negeri 7 Malang, dan SMK Kartika IV-1 Malang pada bidang keahlian Jasa Boga yang sudah melaksanakan PKL sebanyak 199. Teknik pengambilan sampel menggunakan probability sampling dengan sampel sebanyak 127 siswa sebagai responden. Penentuan jumlah sampel tiap sekolah menggunakan proporsional random sampling, SMK Negeri 3 Malang sebanyak 63 responden, SMK Negeri 7 Malang se- 
banyak 43 responden, dan SMK Kartika IV-1 Malang sebanyak 20 responden.

Instrumen yang digunakan dalam penelitian ini adalah angket dengan skala Likert, dan instrument diujicobakan kepada 30 siswa di SMK Negeri 1 Batu pada bidang keahlian Jassa Boga yang sudah melaksanakan PKL untuk kemudian diuji kelayakan meliputi uji validitas dan uji reliabilitas. Data terlebih dahulu dilakukan uji asumsi klasik dan yang telah lolos uji asumsi klasik dilanjutkan dengan analisis regresi sederhana dan analisis faktor.

\section{HASIL}

PKL di Kota Malang dilaksanakan pada saat siswa duduk di kelas XI. Tempat yang dijadikan institusi pasangan (IP) antara lain, hotel, catering, restoran dan bakery. Bagian yang ditempati terdiri dari bagian pelayanan makanan dan minuman serta bagian produksi. Pengambilan data penelitian dilakukan di tiga sekolah menengah kejuruan di Kota Malang, yaitu SMK Negeri 3 Malang, SMK Negeri 7 Malang dan SMK Kartika IV-1 Malang.

Hasil uji normalitas dapat dilihat pada Tabel 1 dan Gambar 1. Hasil uji heteroskedastisitas dapat dilihat pada Tabel 2 dan Gambar 2. Hasil uji linieritas dapat dilihat pada Tabel 3 dan Gambar 3. Hasil analisis regresi linier sederhana dapat dilihat pada Tabel 4.
Normal P-P Plot of Regression

Standardized Residual

Dependent Variabel: Soft Skill

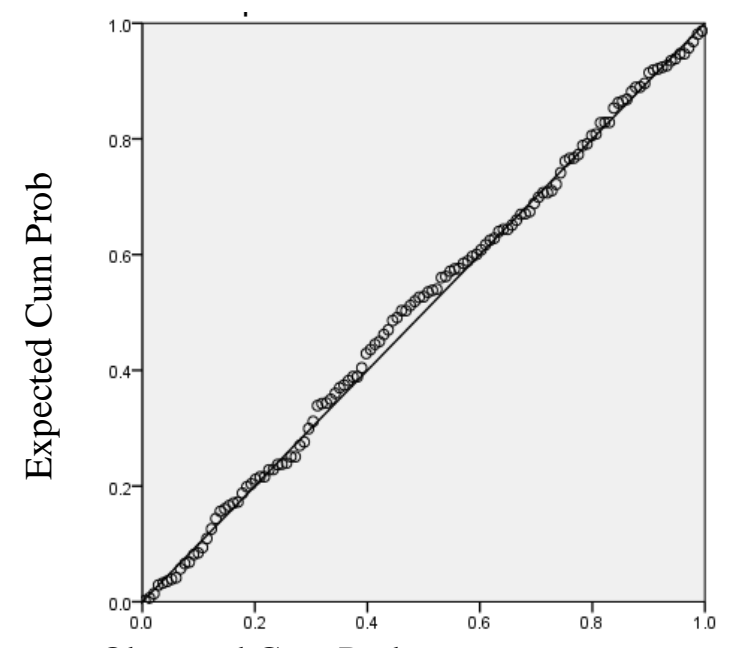

Observed Cum Prob

Gambar 1. Hasil Uji Normalitas P-P Plot

Scatterplot

Dependent Variabel: Soft Skill

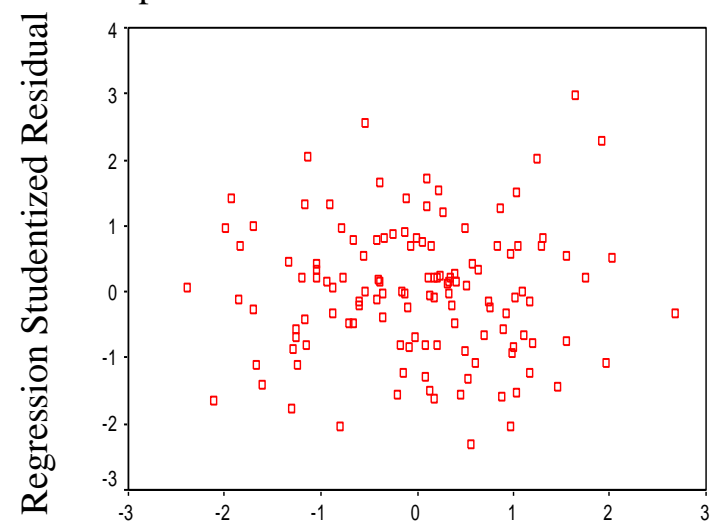

Regression Standardized Predictor Value

Gambar 2. Hasil Uji Heteroskedastisitas Scatterplot

Tabel 1. Hasil Uji Normalitas

\begin{tabular}{llll}
\hline No & Item & PKL & Soft Skill \\
\hline $\mathrm{N}$ & & 127 & 127 \\
Normal Parameters a.b & Mean & 64.76 & 123.98 \\
& Std. Deviation & 9.734 & 12.482 \\
Most Extreme & Absolute & .134 & .131 \\
Differences & Positive & .104 & .051 \\
& Negative & -.134 & -.131 \\
Kolmogorov-Smirnov Z & & .581 & .641 \\
Asymp. Sig (2-tailed) & & .889 & .807 \\
\hline
\end{tabular}

a. Test Distribution is Normal

b. Caculated from Data 
Tabel 2. Hasil Uji Heteroskedastisitas

\begin{tabular}{llllll}
\hline Model & \multicolumn{2}{l}{$\begin{array}{l}\text { Unstandardized } \\
\text { Coefficients }\end{array}$} & $\begin{array}{l}\text { Standardized } \\
\text { Coefficients }\end{array}$ & t & Sig. \\
\cline { 2 - 4 } & $\mathbf{B}$ & Std. Error & Beta & & \\
\hline 1 (Constant) & 5.253 & 3.186 & & 1.648 & .102 \\
PKL & .027 & .049 & .049 & .546 & .586 \\
\hline
\end{tabular}

a. Dependent Variable: RES_2

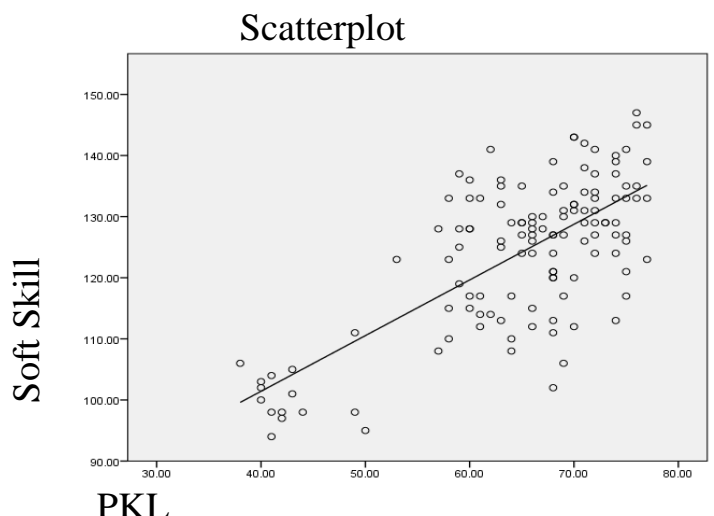

Gambar 3. Hasil Uji Linieritas Scatterplot

Nilai koefisien pada Tabel 4 sebesar 0,911 dengan signifikansi $0,000<$ alpha $=0,05$ yang berarti terdapat hubungan positif antara praktik kerja lapangan sebagai variabel independen terhadap soft skill sebagai variabel dependen.

Hasil Uji KMO dan Bartlett's Test dapat dilihat pada Tabel 5. Berdasarkan pengujian diatas dapat diketahui bahwa KMO mempunyai nilai $>0,5$ yaitu 0,542 . Apabila dilihat dari nilai Bartlett's Test of Sphericity sebesar 181,271 dengan signifikasi sebesar 0,000 menunjukkan terdapat korelasi yang signifikan antara variabel dari matrik korelasi yang terbentuk.

Ekstraksi faktor dapat dilihat pada Tabel 6 communalities. Tabel 6 menunjukkan bahwa keterampilan komunikasi tertulis bisa dijelaskan oleh faktor yang terbentuk sebesar $73,90 \%$, keterampilan berpikir kritis sebesar 88,40\%, keterampilan pemecahan masalah, sebesar 93,60\%, dan keterampilan memahami antar pribadi sebesar 76,20\%.

Hasil penentuan jumlah faktor didasarkan pada faktor yang memiliki nilai eigenvalue lebih dari 1 dapat dilihat pada Tabel 7.

Tabel 3. Hasil Uji Linearitas

\begin{tabular}{llllllll}
\hline & & & $\begin{array}{l}\text { Sum of } \\
\text { Squares }\end{array}$ & df & $\begin{array}{l}\text { Mean } \\
\text { Squares }\end{array}$ & F & Sig. \\
\hline Soft Skill* & Between & (Combined) & 12554.742 & 29 & 432.922 & 5.934 & .000 \\
PKL & Groups & Linearity Deviation & 9911.418 & 1 & 9911.418 & 135.865 & .000 \\
& & from Linearity & 2643.325 & 28 & 94.404 & 1.294 & .178 \\
& Within & & 7076.187 & 97 & 72.950 & & \\
& Groups & & 19630.929 & 126 & & & \\
\hline
\end{tabular}

Tabel 4. Hasil Analisis Regresi Linier Sederhana

\begin{tabular}{llcclll}
\hline Model & \multicolumn{2}{l}{ Unstandardized Coefficients } & \multicolumn{2}{l}{$\begin{array}{l}\text { Standardized } \\
\text { Coefficients }\end{array}$} & & \\
\cline { 1 - 4 } & & B & Std. Error & Beta & t & Sig. \\
\hline 1 & (Constat) & 64.976 & 5.284 & & 12.297 & .000 \\
& PKL & .911 & .081 & .711 & 11.290 & .000 \\
\hline
\end{tabular}

a. Dependent Variable : Soft Skill

R Square $\quad: 0,505$

Adjust R Square $\quad: 0,501$ 
Tabel 5. KMO and Bartlett's Test

\begin{tabular}{lll}
\hline \multicolumn{3}{c}{ KMO and Bartlett's Test } \\
\hline Kaiser-Meyer-Olkin Measure of Sampling Adequacy & .542 \\
Bartlett's Test of Sphericity & Approx. Chi-Square & 181.271 \\
& $\mathrm{df}$ & 6 \\
& Sig. & .000 \\
\hline
\end{tabular}

Tabel 6. Communalities

\begin{tabular}{lll}
\hline Sub Variabel Soft Skill & Initial & Extraction \\
\hline Keterampilan Komunikasi Tertulis & 1.000 & .739 \\
Keterampilan Berpikir Kritis & 1.000 & .884 \\
Keterampilan Pemecahan Masalah & 1.000 & .936 \\
Keterampilan Memahami antar Pribadi & 1.000 & .762 \\
\hline
\end{tabular}

Tabel 7. Total Variance Explained

\begin{tabular}{lrccccc}
\hline \multirow{2}{*}{ Component } & \multicolumn{3}{c}{ Initial Eigenvalues } & \multicolumn{3}{c}{ Extraction Sums of Squared Loadings } \\
\cline { 2 - 7 } & Total & $\begin{array}{c}\text { \% of } \\
\text { Variance }\end{array}$ & $\begin{array}{c}\text { Cumulative } \\
\text { \% }\end{array}$ & Total & $\begin{array}{c}\text { \% of } \\
\text { Variance }\end{array}$ & $\begin{array}{c}\text { Cumulative } \\
\text { \% }\end{array}$ \\
\hline 1 & 2.238 & 55.948 & 55.948 & 2.238 & 55.948 & 55.948 \\
2 & 1.083 & 27.070 & 83.019 & 1.083 & 27.070 & 83.019 \\
3 & .481 & 12.015 & 95.034 & & & \\
4 & .199 & 4.966 & 100.000 & & & \\
\hline
\end{tabular}

Tabel 8. Rotated Component Matrix

\begin{tabular}{llc}
\hline & Rotated Component Matrix $^{\mathbf{a}}$ & \\
\cline { 2 - 3 } & \multicolumn{2}{c}{ Component $^{-}$} \\
\hline Komunikasi Tertulis & .855 & .085 \\
Berpikir Kritis & .524 & .781 \\
Pemecahan Masalah & -.028 & .967 \\
Memahami antar Pribadi & .863 & .134 \\
\hline
\end{tabular}

Extraction Method: Principal Component Analysis.

Rotation Method :Varimax with Kaiser Normalization ${ }^{\text {a }}$

Berdasarkan Tabel 7 menunjukkan bahwa dari 4 item terdapat 2 item yang memiliki nilai eigenvalue (varians) lebih besar dari 1, yaitu component 1 sebesar 2,236 dan component sebesar 1,083.

Hasil rotasi faktor dapat dilihat pada Tabel 8. Berdasarkan Tabel 8 dapat disimpulkan yang dimasukkan dalam komponen faktor 1 adalah keterampilan komunikasi tertulis dan keterampilan memahami antar pribadi, sedangkan yang dimasukkan dalam komponen faktor 2 adalah keterampilan berpikir kritis dan keterampilan pemecahan masalah.

\section{PEMBAHASAN}

Berdasarkan temuan penelitian PKL berpengaruh terhadap soft skill (keterampilan komunikasi tertulis, keterampilan berpikir kritis, keterampilan pemecahan masalah, dan keterampilan memahami antar pribadi) siswa SMK Bidang Keahlian Jasa Boga di Kota Malang. PKL yang dilakukan siswa SMK di industri, siswa diharapkan mendapatkan pengetahuan dan keterampilan, baik dalam bekerja maupun bersikap sesuai dengan tuntutan dunia usaha/dunia industri (DU/DI). Hal ini diperkuat oleh penelitian yang dilakukan oleh Mariah dan Sugandi (2010) yang menyatakan bahwa kemampuan soft 
skill bisa diasah dan ditingkatkan seiring dengan pengalaman belajar. Peningkatan tersebut bisa dilakukan dengan tiga cara, yaitu: (1) Pengembangan soft skill melalui pembelajaran afektif, (2) Pengembangan soft skill melalui kegiatan ektrakurikuler serta kesiswaan, dan (3) Pengembangan soft skill melalui praktik kerja industri.

Pernyataan tersebut didukung oleh pernyataan Iyer dan Dave (2015) dalam penelitian yang dilakukan dan menunjukkan bahwa ditemukan bahwa peran industri di dunia kerja sangat penting dan berdampak pada kebijakan makro lainnya. Contoh keterlibatan tersebut mereka adopsi dari model pendidikan di Jerman, dimana sebagian waktu belajar siswa diberikan di industri. Sistem ini akan mendidik keterampilan dan sikap siswa sesuai dengan tuntutan dunia kerja.

Dunia usaha/industri (DU/DI) yang dijadikan institusi pasangan (IP) menurut Retnoningsih (2011) oleh sekolah diantaranya restoran, hotel, catering, dan bakery. Semuanya meliputi bagian produksi dan pelayanan. Indutsri menuntut siswa memiliki soft skill yang meliputi keterampilan komunikasi tertulis, berpikir kritis, pemecahan masalah dan memahami antar pribadi.

Siswa akan mendapatkan tugas atau job disk dari bagian di mana siswa tersebut ditempatkan, jika siswa menempati bagian pelayanan makanan dan minuman akan melatih keterampilan siswa dalam berkomunikasi baik lisan maupun tertulis. Saat siswa tidak memahami menu yang dipresentasikan kemungkinan akan terjadi kesalahan seperti salah menyebutkan komposisi ataupun bahan dari menu yang tertera dan jika siswa tidak terampil saat berbicara, akan mengakibatkan ketidakpahaman pelanggan dengan menu yang dijelaskan. Hal tersebut mengakibatkan adanya kesalahan komunikasi. Pada saat itu ke empat soft skill tersebut dibutuhkan, siswa harus mampu berpikir kritis dan mengkomunikasikannya kepada karyawan atau atasan untuk mendapatkan solusi yang paling tepat terkait masalah yang terjadi.

Sementara jika siswa ditempatkan di bagian produksi baik hot kitchen maupun cold kitchen, tugas diberikan sesuai dengan bagiannya masing-masing. Misalkan saat siswa yang praktik ditugaskan di pastry section, siswa diberikan tugas untuk membantu menimbang bahan untuk pembuatan cake. Secara tidak sengaja siswa tersebut melakukan kesalahan, dan kesalahan tersebut diketahui setelah cake dikeluarkan dari oven dan dilihat langsung oleh pastry chef. Kesalahan tersebut menuntut siswa yang praktik untuk berpikir kritis dari mulai menganalisis sampai mengambil keputusan dengan terlebih dahulu berkomunikasi dengan pastry chef terkait solusi yang harus diambil.

Tugas-tugas yang diberikan akan melatih keterampilan siswa dalam hal berkomunikasi dengan atasan, karyawan, sesama teman PKL dan juga pelanggan. Artinya bahwa soft skill siswa SMK meningkat setelah siswa melakukan PKL, walaupun pada kenyataannya pengaruh PKL terhadap soft skill masih relatif kecil, hal ini disebabkan beberapa faktor yang saling berkaitan antara pihak sekolah, industri maupun siswa SMK sendiri. Faktor pertama dikarenakan pihak sekolah mempersiapkan hard skill maupun soft skill siswa secara matang, sehingga pada saat siswa di industri siswa sudah siap dengan tuntutan dunia usaha/dunia industri (DU/DI). Pihak sekolah dalam hal ini mempunyai peranan untuk menentukan tempat praktik kerja lapangan (PKL), maka dari itu pihak sekolah harus mempunyai standar untuk tempat industri yang akan dijadikan institusi pasangan (IP) supaya siswa benar-benar mendapatkan pengalaman belajar dan bekerja sesuai dengan tuntuan dunia usaha/dunia industri (DU/DI). Tempat industri yang tidak sesuai dengan 
standar dikhawatirkan tidak memaksimal -kan perannya sebagai institusi pasangan (IP). Industri yang diharapkan menjadi gambaran siswa SMK tentang dunia kerja, tidak melatih ataupun membimbing siswa terkait soft skill yang harus dimiliki siswa untuk menghadapi tuntutan dunia usaha/dunia industri (DU/DI), hal ini merupakan salah satu menjadi penyebab rendahnya soft skill siswa SMK.

Pernyataan diatas diperkuat oleh pernyataan Rao (2015) yang mengatakan bahwa peran industri dan sekolah sangat penting dalam rangka memberikan pelatihan dan penempatan siswa saat magang. Tetapi pada kenyataannya banyak siswa yang tidak dipersiapkan dengan baik oleh sekolah. Salah satunya karena pelatihaan yang diberikan kepada siswa sudah tidak relevan dengan kebutuhan industri, sehingga harus ada interaksi secara terusmenerus antara sekolah dan industri untuk mengetahui keinginan ataupun kebutuhan dari masing-masing pihak. Oleh karena itu, untuk meningkatkan keterampilan kerja harus ada peran dari semua pemangku kepentingan dari mulai pendidik, siswa, orang tua, pemerintah, organisasi non-pemerintah dan industri.

Faktor yang terakhir berasal dari siswa PKL yang tidak mampu berkembang memenuhi tuntutan DU/DI terkait soft skill yang harus dimiliki yang terdiri dari keterampilan komunikasi tertulis, keterampilan berpikir kritis, keterampilan pemecahan masalah, dan keterampilan memahami antar pribadi. Beberapa faktor tersebut menjadikan siswa kurang mendapatkan pengalaman bekerja dan belajar terkait dengan soft skill yang menjadi tuntutan dunia usaha/dunia industri (DU/ DI), sehingga berdampak pada kualitas lulusan dan kesiapan yang dimiliki SMK. Siswa SMK yang tidak sesuai dengan kualitas dan belum cukup memiliki kesiapan yang diharapkan dunia usaha/dunia industri (DU/DI) sulit untuk mendapatkan pekerjaan, hal ini menjadi-kan bertambahnya pengangguran terbuka berdasarkan pendidikan pada tingkat SMK.

Beberapa faktor tersebut menjadikan siswa kurang mendapatkan pengalaman bekerja dan belajar terkait dengan soft skill yang menjadi tuntutan dunia usaha/dunia industri (DU/DI), sehingga berdampak pada kualitas lulusan dan kesiapan yang dimiliki SMK.

Faktor-faktor diatas dapat diatasi salah satunya dengan cara dilakukannya kolaborasi antara sekolah dan institusi pasangan (IP) yang dalam hal ini adalah industri. Jauhari (2013) menyatakan bahwa cara untuk mengembangkan keterampilan kerja adalah dengan cara kolaborasi antara lembaga pendidikan dengan industri terkait, dimana kolaborasi tersebut memfokuskan pada hasil belajar dan kompetensi yang harus dicapai, sehingga siswa dapat melakukannya dengan baik dalam karir mereka. Jauhari (2013) menambahkan, bahwa keterampilan generik yang harus dimiliki agar sukses di industri khususnya pariwisata dan perhotelan adalah berpikir kritis, kemampuan analisis, skill kepemimpinan, kerja tim, kemampuan berkomunikasi, manajemen diri, keterampilan IT, nilai disiplin dan integritas.

Hal tersebut didukung pernyataan Depdiknas (2004) yang membagi kecakapan hidup menjadi dua, kecakapan hidup generik meliputi: 1) kesadaran diri banyak terkait dengan sikap, 2) kecakapan berpikir, 3) kecakapan komunikasi, dan 4) kecakapan hidup spesifik dan kecakapan spesifik, yang menunjuk dalam bidang yang ditekuni. Pernyataan yang sama juga disampaikan oleh Tsai (2013: 36) terkait hasil penelitiannya yang menyatakan bahwa pengembangan tes keterampilan generik yang digunakan ACER dapat dilakukan melalui empat bidang, yaitu; 1) komunikasi tertulis, 2) berpikir kritis, 3) pemecahan masalah, 4) keterampilan memahami antar pribadi. 
Penelitian ini juga diperkuat oleh Porbaningsih, dkk (2012) bahwa ada pengaruh yang signifikan kegiatan Prakerin terhadap kemampuan penguasaan soft skills siswa kelas XI program keahlian Administrasi Perkantoran SMK Islam Al Hikmah Mayong Jepara. Hal ini sependapat dengan Novianti (2014) yang mengatakan bahwa pengalaman praktik kerja industri (PRAKERIN) berpengaruh positif dan signifikan terhadap tingkat kesiapan kerja siswa sebesar 47,3\%. Ketidaksiapan tersebut disebabkan oleh kurangnya penguasaan keterampilan-keterampilan yang dibutuhkan oleh dunia usaha atau dunia industri (DU/DI) salah satunya adalah soft skill.

Hal tersebut menunjukan bahwa praktik kerja lapangan mempunyai peranan dalam kesiapan soft skill siswa SMK bidang keahlian Jasa Boga yang berada di kota Malang untuk menghadapi dunia kerja khususnya dalam keterampilan komunikasi secara tertulis, hal tersebut sependapat dengan yang disampaikan (Depdiknas, 2004) mengingat bahwa yang dibutuhkan dunia industri adalah lulusan SMK yang memiliki kecakapan hidup (life skill) meliputi hard skill dan soft skill. Suryanto (2013:228) juga menambahkan bahwa kesiapan lulusan untuk memasuki dunia kerja melibatkan tiga faktor, yaitu: 1) fisiologis yang menyangkut kematangan usia, kondisi fisik, dan organ tubuh, 2) pengalaman yang meliputi pengalaman belajar dan bekerja menyangkut pengetahuan dan keterampilan (hard skill), dan 3) psikologis yaitu keadaan mental, emosi, dan sosial (soft skill).

Nisa (2012) dalam penelitiannya mengatakan, ada hubungan yang signifikan antara prestasi belajar Prakerin terhadap kesiapan memasuki dunia kerja siswa kompetensi keahlian Jasa Boga kelas XII SMK Negeri 3 Probolinggo sebesar $53,40 \%$.
Berdasarkan temuan penelitian mengenai empat soft skill yang terdiri dari keterampilan komunikasi tertulis, keterampilan berpikir kritis, keterampilan pemecahan masalah, dan keterampilan memahami antar pribadi siswa SMK di Kota Malang yang sudah melakukan praktik kerja lapangan (PKL), diketahui bahwa keterampilan komunikasi tertulis mempunyai nilai yang paling rendah untuk mewakili soft skill. Hal ini disebabkan beberapa kemungkinan, salah satunya karena indikator yang digunakan dalam angket untuk penelitian.

Keterampilan berpikir kritis merupakan proses mental untuk menganalisis atau mengevaluasi informasi, dimana informasi tersebut didapatkan dari hasil pengamatan, pengalaman, dan komunikasi (Deswani, 2009). Berdasarkan penelitian keterampilan berpikir kritis menempati urutan ke dua terbesar setelah keterampilan pemecahan masalah. Hal ini disebabkan oleh beberapa kemungkinan, salah satunya karena indikator yang digunakan dalam angket.

Keterampilan pemecahan masalah merupakan keterampilan salah satu bagian dari proses berpikir yang berupa kemampuan untuk memecahkan persoalan (Marzano, 1988).

Berdasarkan temuan penelitian, keterampilan pemecahan masalah merupakan keterampilan yang memiliki nilai ekstraksi paling tinggi, sehingga disimpulkan bahwa keterampilan yang paling mewakili soft skill. Hal ini disebabkan oleh beberapa kemungkinan, salah satunya karena indikator yang digunakan dalam angket penelitian.

Keterampilan memahami antar pribadi atau yang biasa disebut interpersonal skill merupakan keterampilan seseorang dalam berhubungan dengan orang lain yang mampu mengembangkan secara maksimal unjuk kerja (performans) seseorang (Sailah, 2008). Berdasarkan temuan penelitian, keterampilan memahami antar pribadi merupakan keteram- 
pilan yang memiliki nilai ekstraksi terbesar ketiga setelah keterampilan pemecahan masalah dan keterampilan berpikir kritis. Hal ini disebabkan oleh beberapa kemungkinan, salah satunya karena indikator yang digunakan dalam angket penelitian.

\section{SIMPULAN DAN SARAN}

Berdasarkan hasil penelitian dan pembahasan, maka kesimpulan pada penelitian ini yaitu: (1) Praktik kerja lapangan (PKL) berpengaruh terhadap soft skill siswa SMK Bidang Keahlian Jasa Boga di Kota Malang. Soft skill yang dibutuhkan oleh industri meliputi keterampilan komunikasi tertulis, berpikir kritis dan pemecahan masalah dan memahami antar pribadi, (2) Keterampilan pemecahan masalah merupakan keterampilan yang paling mewakili soft skill dibandingkan keterampilan komunikasi tertulis, keterampilan berpikir kritis, dan keterampilan memahami antar pribadi pada siswa SMK Bidang Keahlian Jasa Boga di Kota Malang.

Bagi Peneliti selanjutnya dapat melakukan penelitian lebih lanjut tentang praktik kerja lapangan (PKL) dan kemampuan intrapersonal aspek lainnya. (2) Bagi Sekolah, diharapkan sekolah dalam rangka menyiapkan soft skill siswa SMK dalam mengahadapi dunia kerja. agar memenuhi tuntutan dunia usaha/ dunia industri (DU/DI). (3) Bagi lembaga terkait, soft skill merupakan faktor penentu keberhasilan seseorang, lembaga diharapkan ikut berperan menyiapkan mahasiswa yang menempuh program studi pendidikan agar memilliki pengetahuan dan kemampuan terkait soft skill dalam rangka menyiapkan soft skill siswa SMK Bidang Keahlian Jasa Boga dalam menghadapi dunia kerja.

\section{DAFTAR RUJUKAN}

Badan Pusat Statistik. 2015. Tingkat Pengangguran Terbuka Berdasarkan Tingkat Pendidikan di Jawa Timur. (Online), (https://malangkota.bps. go.id, diakses tanggal 05 Oktober 2016).

Basuki. 2012. Korelasi antara Pengalaman Prakerin, Sikap Mandiri dan Prestasi Belajar Bidang Produktif dengan Kesiapan Kerja Siswa Kelas XII Program Keahlian Teknik Mesin (TM) di SMK Negeri 6 Malang. Jurnal Teknik Mesin, 20(2): 1--15. (Online), (http://journal.um.ac.id, diakses 05 Mei 2016).

Deswani. 2009. Proses Keperawatan dan Berpikir Kritis. Jakarta: Salemba.

Dikmenjur. 1996. Konsep Pendidikan Sistem Ganda pada SMK di Indonesia. (Online), (http://listpdf.com.pe/ pendidikan-sistem-ganda-di-smkpdf.html, diakses 23 Mei 2016).

Dikmenjur. 2012. Pedoman Pelaksanaan Prakerin. Jakarta: Dikmenjur.

Direktorat Jendral Pendidikan Dasar dan Menengah. 2015. Panduan Penilaian pada Sekolah Menengah Kejuruan. Jakarta: Kementrian Pendidikan dan Kebudayaan.

Iyer, V.M. \& Dave, K. 2015. Industry's Role in Employability. Journal Industrial and Commercial Training, 47(3): 151--158, (Online), (http://dx. doi.org/10.1108/ICT-11-2014-0072, diakses 15 Maret 2016).

Jauhari, V. 2013. Building Employability in Hospitally Industry. Journal Worldwide Hospitality and Tourism Themes, (Online), 5(3): 268--276, (http://dx.doi.org/10.1108/WHATT02-2013-0009, diakses 15 Maret 2016).

Mariah, S. \& Sugandi, M. 2010. Kesenjangan Soft Skill Lulusan SMK dengan Kebutuhan Tenaga Kerja di Industri. Jurnal Inovasi dan Perekayasa Pendidikan, 3(1): 379--400. 
(Online), (http://isjd.pdii.lipi.go.id/ admin/jurnal/1310379400_2087150 3.pdf, diakses 27 Januari 2013).

Marzano, R.J. et all. 1966. Dimension of Thinking: A Framework for Curriculum and Instruction. Viginia: Association for Supervision and Curriculum Development. (Online), diakses 31 Agustus 2016.

Retnoningsih, D. 2011. Pelaksanaan Praktik Industri Sebagai Upaya Peningkatan Kesiapan Kerja Pada Siswa Program Keahlian Tata Boga SMK N 1 Sewon. Skripsi Tidak Diterbitkan. Yogyakarta: Pendidikan Teknik Boga UNY.

Sailah, I. 2008. Pengembangan Soft Skills di Perguruan Tinggi, (Online), (http://undana.ac.id/jsmallfib_top/LP MPTBUKUDIKTI/BUKU\%SOFTS KILL.pdf, diakses 05 Mei 2016).
Tsai, C.Y. 2013. Graduate Institute of Education Administration, National Ping-Tung University of Education. Journal of Sociological Research, 4(2): 1948--5468, (Online), (http:// www.macrothink.org/journal/index. php/jsr/article/download/4481/3690, diakses 15 Maret 2016).

Utaminingsih, S. 2011. Model Manajemen Pengembangan Soft Skill SMK Program Keahlian Pariwisata. Jurnal Pendidikan Ekonomi Dinamika Pendidikan, 6(2):169--133, (Online), (https://media.neliti.com/media/publ ications/61195-ID-pengembangansoft-skill-berbasis-karir-p.pdf, diakses 05 Mei 2016). 